\title{
Tecnologias Digitais aplicadas ao Patrimônio Cultural e ao Turismo
}

\author{
Digital Technologies applied to Cultural Heritage and Tourism \\ Tecnologías Digitales aplicadas al Patrimonio Cultural y al Turismo
}

Sandra Schmitt Soster

Universidade de São Paulo (USP), Brasil

soster.heritage@gmail.com

Pedro Henrique Gonçalves

Universidade Federal de Goiás (UFG), Brasil

pedrogoncalves@ufg.br

Ariane Magda Borges

Universidade Federal de Goiás (UFG), Brasil

arianeborges@ufg.br
DOI: https://doi.org/10.18472/cvt.21n2.2021.1945

Redalyc: https://www.redalyc.org/articulo.oa?

$\mathrm{id}=115468015009$

Recepción: 02 Junio 2021

Aprobación: 29 Julio 2021

\section{Resumo:}

As Tecnologias Digitais permitem a ampla circulação da informação e a alteração do modelo de ensino/aprendizagem vigente desde a Idade Média, especialmente porque os ambientes virtuais estão cada vez mais realísticos e interativos. Contudo, essas tecnologias ainda são pouco utilizadas na área do patrimônio cultural, em especial para promoção e realização de visitação turística junto a instituições e sítios históricos. Nesse contexto, este artigo procura desmistificar a complexidade de algumas tecnologias para incentivar seu uso entre gestores turísticos e patrimoniais. São apresentados projetos realizados pelos autores e estudos de caso, que abrangem desde a disponibilização de informações georreferenciadas em websites, até tecnologias tidas como mais complicadas, como fotogrametria, realidade aumentada e gamificação.

Palavras-ChaVE: Patrimônio cultural, Turismo, Fotogrametria, Realidade aumentada, Gamificação.

\section{ABSTRACT:}

Digital Technologies support the wide circulation of information and a shift in the teaching/learning method used since the Middle Ages, especially because virtual environments are increasingly realistic and interactive. However, these technologies are still little used in the area of cultural heritage, especially for promoting and carrying out tourist visits to historical institutions and sites. In this context, this paper aims to demystify the complexity of some technologies to encourage their use among tourism and heritage managers. Projects carried out by the authors and case studies are presented, ranging from the provision of georeferenced information on websites, to technologies considered more complicated, such as photogrammetry, augmented reality and gamification.

KeYworDs: Cultural heritage, Tourism, Photogrammetry, Augmented reality, Gamification.

\section{RESUMEN:}

Las Tecnologías Digitales permiten la amplia circulación de información y cambian el modelo de enseñanza / aprendizaje vigente desde la Edad Media, especialmente porque los entornos virtuales son cada vez más realistas e interactivos. Sin embargo, estas tecnologías aún son poco utilizadas en el ámbito del patrimonio cultural, especialmente para promover y realizar visitas turísticas en instituciones y sitios históricos. En este contexto, este artículo busca desmitificar la complejidad de algunas tecnologías para incentivar su uso entre los gestores turísticos y patrimoniales. Se presentan proyectos realizados por los autores y estudios de caso, que van desde la provisión de información georreferenciada en sitios web, hasta tecnologías consideradas más complicadas, como la fotogrametría, la realidad aumentada y la gamificación.

Palabras clave: Patrimonio cultural, Turismo, Fotogrametría, Realidad aumentada, Gamificación. 


\section{INTRODUÇÃO}

Iniciamos nossa discussão, refletindo sobre as profundas alterações sociais acarretadas pelas Tecnologias Digitais de Informação e Comunicação (TDIC). Ao ser disponibilizada em ambientes digitais, a informação se torna acessível a todos que possuam um dispositivo e rede de acesso à Internet. $\mathrm{O}$ indivíduo passa a ter o potencial de atuar não somente na recepção do conhecimento (tendo à disposição inúmeros canais de informação) como também em sua emissão. Nos anos 1990, se dizia que essa atuação se dá a nível "glocal": um ambiente de comunicação em tempo real e de justaposição entre o local e o global, pois o indivíduo se encontra no espaço físico local e, ao mesmo tempo, atua no espaço virtual global (Virilo, 1993; Trivinho, 2001). Contudo, para os chamados "nativos digitais" (Palfrey \& Gasser, 2011) - gerações mais recentes, que tiveram contato com a Internet e os dispositivos móveis desde a infância ou o nascimento -, essa distinção entre o físico e o virtual já não é mais perceptível. O virtual se fundiu tanto ao cotidiano, que já não é mais percebido como instância auxiliar.

Esse caráter utilitário e complementar do virtual também é uma potente ferramenta para instituições das mais variadas finalidades e proporções. $\mathrm{Na}$ área do patrimônio cultural, por exemplo, tem uso tanto para museus e outros espaços de visitação quanto para rotas culturais. E, estando o patrimônio cultural ainda muito atrelado aos bens materiais, utilizamos o contexto das edificações históricas para analisar a evolução da incorporação da computação à área de arquitetura.

Como apresentamos na Figura 1, adaptada de Pratschke (2019), nos anos 1980, iniciaram-se as aproximações da área de Arquitetura com a Computação; o que incluiu demandas pela criação de programas específicos para a representação de edificações. $\mathrm{Na}$ década seguinte, os esforços foram alinhados para o melhoramento do design das interfaces dos programas e a organização e a visualização da informação; ampliando a interatividade e a conectividade. Nos anos 2000 , viu-se a mudança de paradigma da computação com a melhoria da Internet, dos dispositivos móveis e da compatibilidade entre os programas; período em que se intensificou a virtualização em três dimensões.

\begin{tabular}{|c|c|c|c|}
\hline $\begin{array}{l}\text { REPRESEN- } \\
\text { TAÇÄO }\end{array}$ & $\begin{array}{l}\text { CONECTIVIDADE } \\
\text { INTERCONEC- } \\
\text { TIVIDADE }\end{array}$ & $\begin{array}{l}\text { HIBRIDIZAÇÃO } \\
\text { VIRTUALIZAÇÃO }\end{array}$ & $\begin{array}{l}\text { PERFORMANCE } \\
\text { SIMULAÇÃO }\end{array}$ \\
\hline 1980 & & 000 & 2020 \\
\hline $\begin{array}{l}\text { Computadores stand- } \\
\text { alone, aproximaçōes } \\
\text { entre arquitetura e } \\
\text { computaçăo, } \\
\text { demanda por } \\
\text { programas }\end{array}$ & $\begin{array}{l}\text { Design de interface, } \\
\text { visualização, } \\
\text { organizaçăo da } \\
\text { informaçăo, } \\
\text { integraçăo }\end{array}$ & $\begin{array}{c}\text { Desenvolvimento } \\
\text { computacional: redes, } \\
\text { distribuiçăo, } \\
\text { mobilidade, } \\
\text { compatibilidade entre } \\
\text { programas, } 3 \mathrm{D}\end{array}$ & $\begin{array}{c}\text { Automaçăo, } \\
\text { otimização, } \\
\text { adaptação, IA, GIS, } \\
\text { BIM, design } \\
\text { paramétrico, } \\
\text { fabricaçãa digital }\end{array}$ \\
\hline
\end{tabular}

A evolução da incorporação da computação à área de arquitetura Fonte: Adaptado de Pratschke (2019).

Nos anos 2010, o foco esteve na melhoria da performance das máquinas, da rede e dos programas, dando impulso a simulação, automação, otimização e adaptação. O Sistema de Informação Geográfica (do inglês, Geographic Information System - GIS) e os aparelhos com Sistema de Posicionamento Global (do inglês, Global Positioning System - GPS) nos permitem viajar ao redor do mundo sem mapas físicos. Programas baseados em Modelagem da Informação da Construção (do inglês, Building Information Modeling - BIM) permitem uma visão geral da edificação e do processo de construção, além de automatizar diversos cálculos e permitir o trabalho colaborativo entre os diferentes atores que participam do processo. E os usos da Inteligência Artificial (IA) vêm sendo ampliados nas mais diversas áreas, de modo a automatizar ou facilitar atividades, aumentando a performance dos programas e dos cérebros humanos. 
Cada vez mais, as tecnologias são desenvolvidas em direção à gestão da informação e pela informação (mineração e processamento de grandes volumes de dados, big data, open data, open source, crowdsourcing etc.). Sistemas inteligentes baseados em aprendizado de máquina e Inteligência Artificial vêm automatizando e potencializando processos antes dependentes do cérebro humano e contribuindo para a tomada de decisões por meio de conhecimento produzido artificialmente. A tecnologia contribui de forma cada vez mais complexa para os conhecimentos humanos, inclusive nas áreas culturais, como contextualizou Gilberto Gil, então Ministro da Cultura:

Cultura digital é um conceito novo, que parte da ideia de que a revolução das tecnologias digitais é, em essência, cultural. O que está implicado aqui é que o uso de tecnologia digital muda os comportamentos. O uso pleno da Internet e do software livre cria fantásticas possibilidades de democratizar os acessos à informação e ao conhecimento, maximizar os potenciais dos bens e serviços culturais, amplificar os valores que formam o nosso repertório comum e, portanto, a nossa cultura, e potencializar também a produção cultural, criando inclusive novas formas de arte (Gil, 2004 como citado em Pratschke, 2019, p. 3).

Em relação aos espaços de memória,

[...] a importância da informação naquilo que se tornou quase uma tríade sagrada - informação, educação e entretenimento - foi completamente reconhecida, muito antes da popularização dos termos "sociedade da informação" e "tecnologia da informação”, durante as décadas de 1970 e 1980 (Briggs \& Burke, 2004, p. 193).

A essa tríade informar-educar-entreter, diretamente relacionada à divulgação na área do patrimônio cultural, adicionaríamos ainda a importância da informação e a utilidade das novas tecnologias em ações de pesquisa, registro e conservação. Até os anos 2000, algumas das principais aplicações tecnológicas difundidas entre as instituições da área eram bibliotecas eletrônicas (processos básicos, índices online, busca de textos completos, recuperação e armazenamento de registros; armazenagem, recuperação e disponibilização da informação; digitalização de livros etc.), bibliotecas digitais (concentram informações existentes apenas em formato digital) e bibliotecas virtuais (reproduzem virtualmente o ambiente físico, em duas ou três dimensões) (Marchiori como citado por Camargo \& Santos, 2005). Por seu potencial como meio de divulgação, os espaços museológicos virtuais são cada vez mais comuns desde os anos 2000, como forma de ampliar o acesso da população aos acervos de tais instituições (Macdonald, 2006), não somente de livros, mas de quaisquer outros objetos.

A partir dos anos 2010, por conta dos avanços do desenvolvimento computacional que comentamos, especialmente aqueles envolvendo tecnologias em 3D, muitos espaços museais introduziram a Realidade Aumentada em suas ações de educação patrimonial (como é o caso da Casa Batló, na Espanha). No mesmo período, com o intuito de promover maior engajamento e interesse do público no âmbito patrimonial, museal e/ou turístico, outras iniciativas passaram a fazer uso de jogos educativos, serious games ou mesmo processos gamificados, isto é, utilizar elementos de jogos em contextos que, a princípio, não têm qualquer relação com este universo.

Entendemos que tais tecnologias possuem grande potencial para a promoção e a realização de visitação turística. Por isso, a fim de desmistificar a complexidade de algumas tecnologias para incentivar seu uso entre gestores turísticos e patrimoniais, a seguir são apresentados projetos realizados pelos autores, que abrangem desde a disponibilização de informações georreferenciadas em websites, até tecnologias tidas como mais complicadas, como fotogrametria, realidade aumentada e gamificação.

Cabe aqui apresentar dois conceitos fundamentais que permeiam as discussões. Informação é entendida como o resultado do processamento de dados e, se absorvida de forma adequada pelo indivíduo, é capaz de gerar conhecimento. Benefícios ao desenvolvimento de uma sociedade são realizados como consequência do modo como o conhecimento é utilizado. Virtualização é entendida aqui como processos de conversão de dados, informações e conhecimentos analógicos em mídias digitais - o que promove maior eficiência dos sistemas computacionais, possibilitando que os recursos sejam mais facilmente ajustados às necessidades 
daqueles que os utilizam; por exemplo, maquetes virtuais intensificam o acesso e a gestão da informação de bens edificados.

\section{MAPAS, ROteiros tURísticos E PlaneJAMENTO REgIONAL}

O iPatrimônio (www.ipatrimonio.org) é um projeto voluntário, sem vínculo institucional e autofinanciado[1], que tem como missão o georreferenciamento de todo o patrimônio cultural oficializado no Brasil. Atualmente, a plataforma reúne informação sobre quase 13 mil bens protegidos por leis mundiais (Organização das Nações Unidas para a Educação, a Ciência e a Cultura - UNESCO), regionais (Mercado Comum do Sul - Mercosul), nacionais (Instituto do Patrimônio Histórico e Artístico Nacional - IPHAN), do Distrito Federal, de todos os Estados brasileiros e de quase 800 municípios (listas em: http://bit.ly/ ipatrimonio_listas).

Ao longo dos trabalhos realizados, constatamos que muitas instituições de grande importância para a sociedade não possuem sites ou informações de contato facilmente localizáveis online. Ao procurar pelo contato das instituições, as buscas não retornam sites oficiais e, como o link do iPatrimônio é sugerido entre os primeiros resultados, o usuário opta por entrar em contato com a plataforma para solicitar históricos escolares, certidões de nascimento, casamento e falecimento e informação sobre sepultamentos; além de solicitação de agendamentos de visitas e orientações de como chegar a museus e fazendas históricas. $\mathrm{O}$ que demonstra a importância de sites claros e completos, respectivamente, de escolas, igrejas, cemitérios e instituições de memória. Sugerimos que as páginas online apresentem ao menos informações básicas de localização, contato e dados sobre visitação. As páginas podem ser websites ou mesmo redes sociais (de fácil alimentação e divulgação e com altas taxas de acesso). Outra iniciativa importante é manter atualizadas as informações retornadas pelo Google (Figura 2).

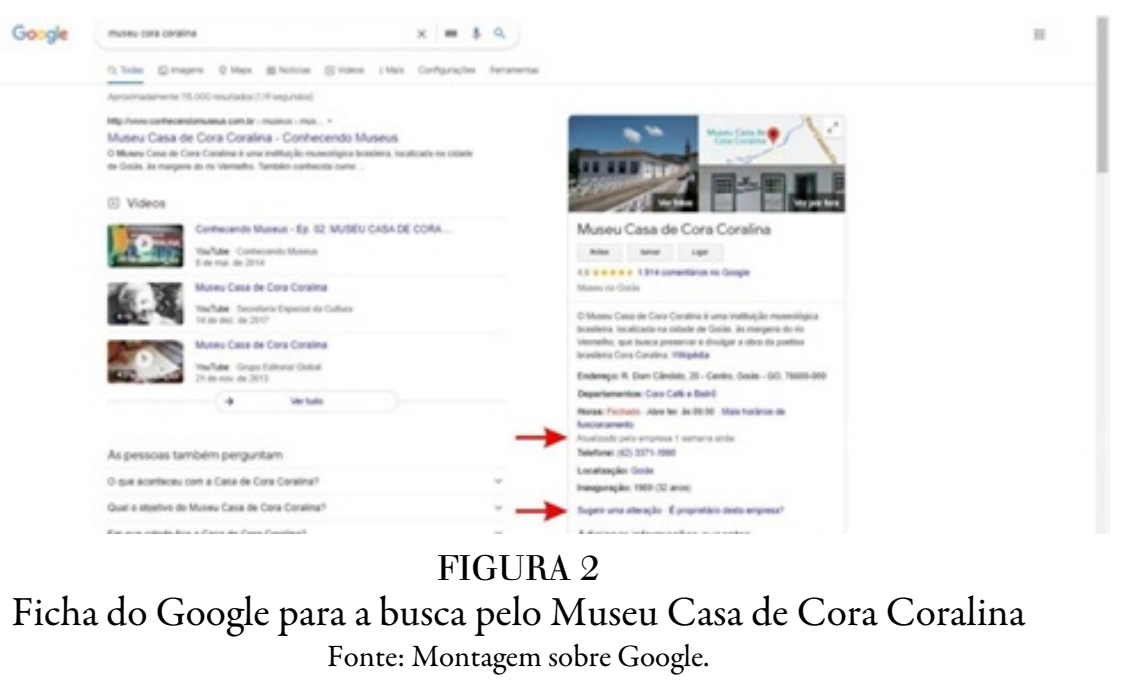

Ao lado direito dos resultados da pesquisa, abre-se uma ficha com diversos dados. A instituição mostrada na Figura 2 atualizou os dados recentemente ("Atualizado pela empresa 1 semana atrás”); o que é realizado clicando em "Sugerir uma alteração". Abre-se uma janela suspensa com a opção "Alterar o nome ou outros detalhes”, dentre os quais está a localização, que inclui mapa com visualização do marcador.

A importância das coordenadas geográficas extrapola o contexto individual de cada bem tombado. Quando vários bens são georreferenciados sobre o mesmo mapa (como no iPatrimônio, onde cerca de 8.500 bens estão georreferenciados), o usuário pode visualizar o contexto de um determinado conjunto de bens. Por exemplo, na Figura 3, são mostrados três bens tombados da área central de Macapá. Com essa informação visual, o turista pode traçar um pequeno roteiro particular. De forma análoga, gestores públicos e institucionais 
poderiam criar mapas Google com bens de rotas culturais específicas, criando mapas regionais de roteiros turísticos (Figura 3).

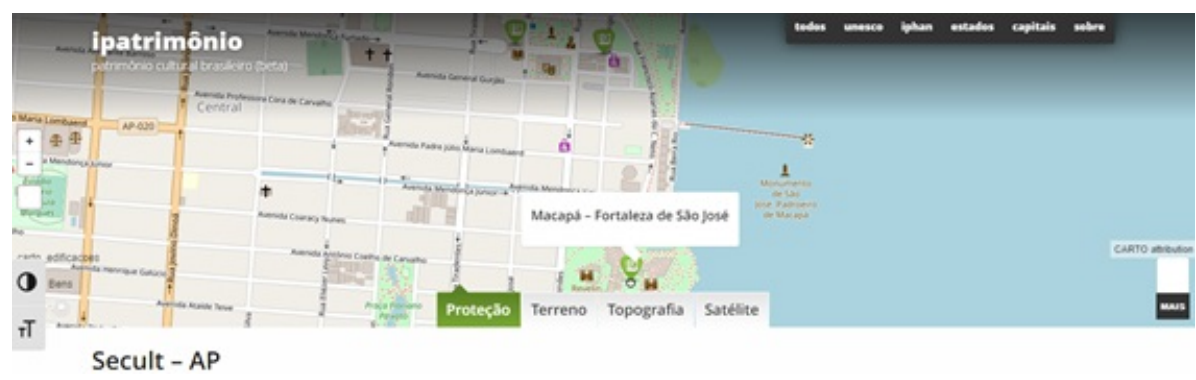

FIGURA 3

Três bens tombados da cidade de Macapá-AP

Fonte: www.ipatrimonio.org/category/secult-ap.

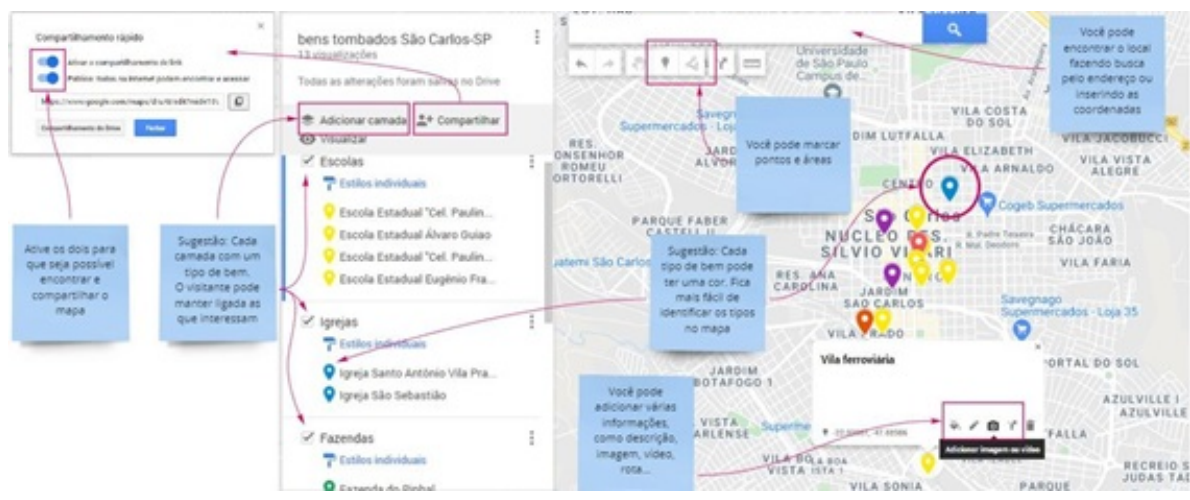

FIGURA 4

Criação de mapa online no Google Maps

Fonte: Montagem sobre Google Maps (www.google.com.br/maps).

A partir de uma conta Gmail, clique em Importar imagen > Seus lugares > MAPAS > CRIAR MAPA.É possível criar pontos e marcar áreas contendo descrição, imagens, vídeos, áudios e rotas. Cada ponto é inserido individualmente, realizando busca pelo endereço ou coordenada. Sugerimos que sejam criadas camadas com os diferentes tipos de bens ou rotas sugeridas; assim o turista pode escolher segundo temas de seu interesse. É preciso habilitar o compartilhamento e a visualização pública do mapa. Além disso, os mapas podem ser colaborativos (com usuários específicos ou aberto ao público em geral). Ao permitir a inclusão de diferentes mídias a um determinado ponto, esses mapas auxiliam na difusão de memórias e conhecimentos, além de entregar informação e experiência para pessoas que não podem estar fisicamente presentes nesses locais.

O entendimento visual da distribuição dos bens nesses mapas é útil também para ações de planejamento urbano e regional na área do patrimônio cultural, tais como a criação de roteiros e a estimativa de verbas de turismo a serem destinadas para cada localidade. Além disso, as áreas vazias do mapa instigam a realização de levantamentos e inventários dos bens culturais existentes nessas regiões. Um exemplo de planejamento regional na área do turismo com foco no patrimônio cultural é o projeto "Arqueologia Social Inclusiva Educar pelo patrimônio nos Museus Orgânicos do Cariri”.

[...] Museus Orgânicos no Cariri que são expressões dinâmicas da criatividade humana, cenários ativos da cultura e do saber fazer popular, abertos nas casas dos mestres que os recebem da herança de seus ancestrais. Implementada na Região do Cariri, Nordeste do Brasil, a ideia, [foi] gerada na Fundação Casa Grande [...] (dos Santos, s.d., s.p.).

O projeto tem como principal objetivo criar uma rede sociocultural composta de lugares de memórias vivas, fomentando a troca de experiências, fortalecimento de vínculos comunitários, intercambiando conhecimentos, gerando conteúdos e oportunidade de geração de renda aos Mestres, seus familiares, agregados e comunidade, tendo como matriz principal a arquitetura do afeto e ativação de territórios criativos. 
A valorização da vida e obra dos mestres, somadas ao incentivo ao conhecimento da cultura popular e às possibilidades para a indução da economia criativa, turismo social e experiências comunitárias, trabalham de forma orgânica em benefício da sustentabilidade do modo vida dos mestres; da existência dos terreiros e das tradições culturais (Mestre Dinha, s.d., s.p.).

O projeto já implementou 10 dos 17 museus previstos, que se distribuem em três categorias (museu-casa, museu-oficina ou museu-casa-oficina), a depender do uso dos espaços cedidos pelos moradores / mestres dos saberes e custando menos de R $\$ 10$ mil cada (Quindins \& Sousa, 2021). Dentre eles estão oficinas onde se mantêm modos de fazer selas (Mestre Espedito), máscaras (Mestre António Luiz), aviões de brinquedo (Mestre Françuli), bacamartes artesanais (Mestre Nena) e redes (Mestra Dinha); e casas onde se preservam saberes como música e dança do povo Kariri (Mestre Raimundo Aniceto) e danças populares (Mestra Zulene) (Barros, 2021). A Fundação Casa Grande registrou alguns desses espaços em vídeo 360 (exemplo em: http:// bit.ly/DonaDinha).

\section{Fotogrametria E MAQUETES VIRTUAis}

A fotogrametria é uma tecnologia bastante difundida no setor do patrimônio cultural para registro e divulgação de elementos urbanos históricos. Essa técnica pode ser realizada de modo profissional ou amador para "[...] a documentação precisa de pequenos objetos, de edificações ou mesmo de áreas urbanas, a depender do tipo de foto (terrestre, aérea ou orbital) e da técnica utilizada [...]" (Arruda, 2013, p. 100-101). O Chafariz da Carioca, na cidade de Goiás-GO - também conhecida como Goiás Velho, foi virtualizado pelo projeto ReDigital (Figura 5).

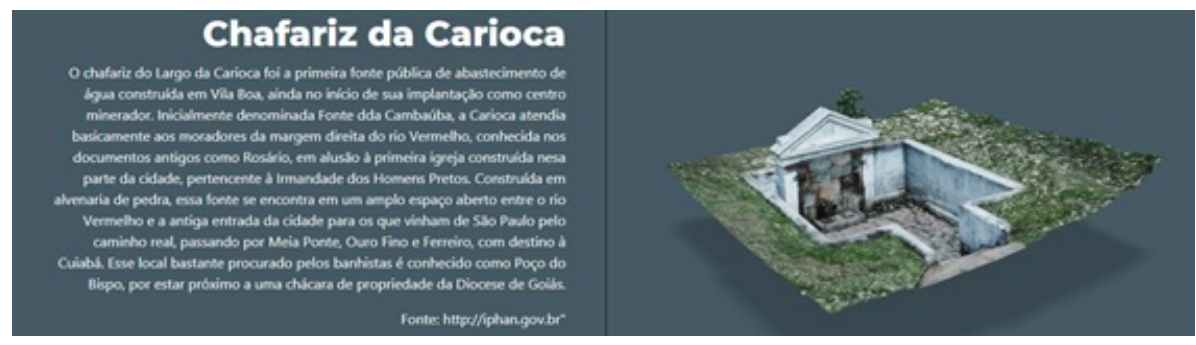

FIGURA 5

Maquete virtual do chafariz da carioca gerada por fotogrametria Fone: http://labam.dev/Goyaz\%20Digital/redigita.

O número de imagens envolvidas é variável, sendo [...] tomadas de ângulos diferentes, com área de superposição, de modo a viabilizar a visão estereoscópica (tridimensional), que possibilita uma maior acurácia na restituição tridimensional do espaço objeto (Brito \& Coelho, 2002, p. 9). Os levantamentos fotográficos devem circundar o elemento escolhido (Figura 6) e, se possível, as fotografias devem ser tiradas em dias distintos, por volta do horário do meio-dia com sol a pino, com céu nublado ou ensolarado. Para a criação do objeto em ambiente virtual (Figura 7), as fotografias são colocadas em algum programa específico que alinha automaticamente as fotos e identifica o posicionamento da câmera (Figura 6) e gera (1) uma nuvem de pontos esparsa e, depois, (2) uma nuvem de pontos densa. Nesse último produto, um algoritmo identifica os pontos e extrai (3) uma malha, que é triangulada para formar polígonos. O produto visualmente mais realístico constitui (4) um mapa de texturas formado por pequenos pedaços das fotografias com pontos de sobreposição e organizados sobre a malha tridimensional; gerando modelo tridimensional colorido e simulação de textura. Os principais programas são Pix4D Mapper, AutoDesk ReCap, Agisoft PhotoScan e Agisoft Metashape 3D. Para iniciantes sugerimos Trnio ou Qlone. 


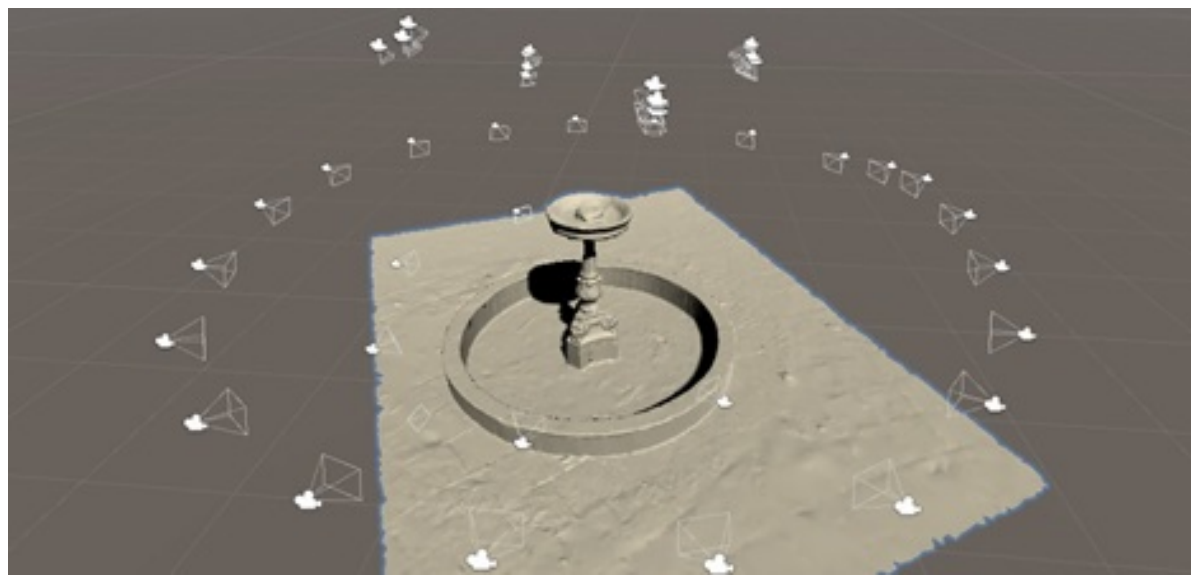

FIGURA 6

Fotos realizadas para a digitalização da Fonte da Praça do Coreto

Fonte: Acervo da pesquisa (2021).

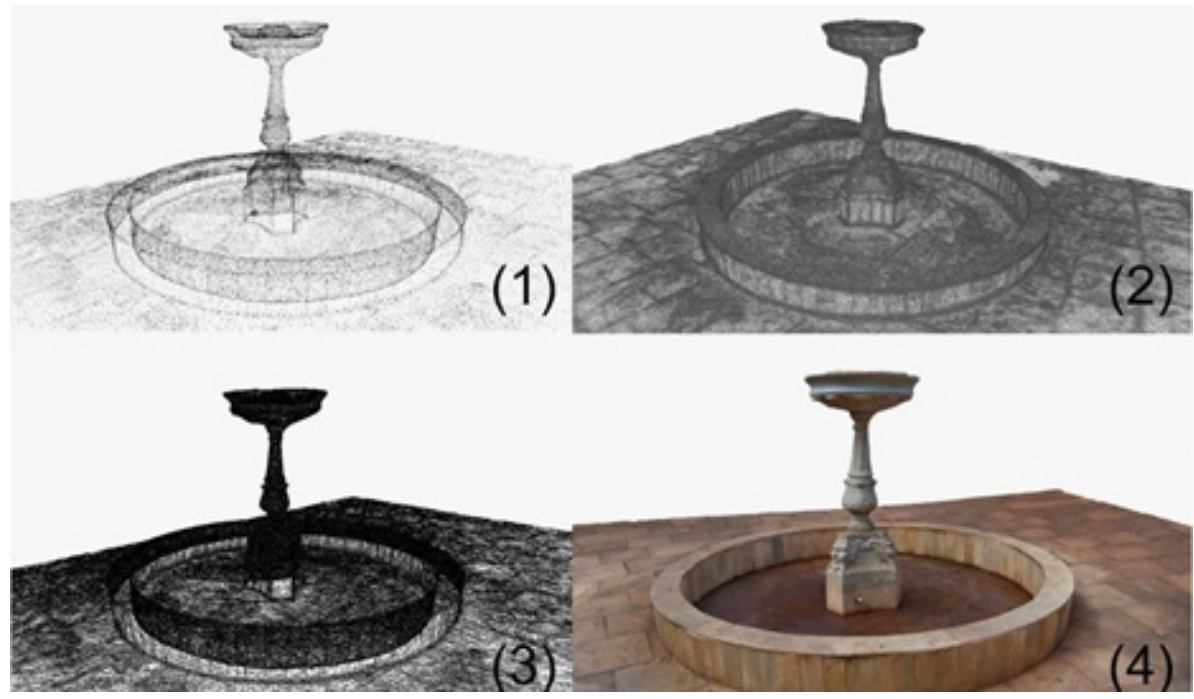

\section{FIGURA 7}

Etapas da criação da Fonte da Praça do Coreto em ambiente virtual Fonte: Acervo da pesquisa (2021).

Tais modelos virtuais são úteis para o levantamento físico-arquitetônico de edificações, facilitando a obtenção de alturas e de medidas dos detalhes. Apresentamos comparação entre os principais métodos de levantamento no Quadro 1.

\section{QUADRO 1}

Características dos três tipos de levantamento físico-arquitetônico

\begin{tabular}{|l|l|l|}
\hline Levantamento & Instrumentos & Requisitos \\
\hline $\begin{array}{l}\text { Direto } \\
\text { (longimétrico) }\end{array}$ & $\begin{array}{l}\text { Trenas, fitas métricas, } \\
\text { niveis, prumo etc. }\end{array}$ & $\begin{array}{l}\text { Todos os pontos de levantamento } \\
\text { devem ser fisicamente acessiveis }\end{array}$ \\
\hline $\begin{array}{l}\text { Instrumental } \\
\text { (topográfico) }\end{array}$ & $\begin{array}{l}\text { Teodolito, scanner laser, } \\
\text { taquimetro, estação } \\
\text { total etc. }\end{array}$ & $\begin{array}{l}\text { Todos os pontos de levantamento } \\
\text { devem ser visiveis através dos } \\
\text { instrumentos de levantamento }\end{array}$ \\
\hline $\begin{array}{l}\text { Indireto } \\
\text { (fotogramétrico) }\end{array}$ & $\begin{array}{l}\text { Máquina fotográfica } \\
\text { comum, programa de } \\
\text { fotomodelagem e de } \\
\text { desenho técnico }\end{array}$ & $\begin{array}{l}\text { Todo o plano a ser levantado deve } \\
\text { estar visivel e enquadrado no } \\
\text { fotograma, base do levantamento }\end{array}$ \\
\hline
\end{tabular}


Fonte: Adaptado de ConservaFAU, s.d., s.p.

Tais tecnologias permitem ao usuário uma experiência remota sobre o patrimônio cultural e as maquetes virtuais podem ser utilizadas em outras tecnologias, como ambientes virtuais com objetos de acervos museológicos, impressão de maquetes dos objetos por meio de impressoras 3D (inclusive para pessoas com problemas visuais), produção de aplicativos de realidade aumentada ou jogos virtuais (gamificação).

\section{Realidade aumentada}

A tecnologia da Realidade Aumentada (RA) permite a construção de experiências de maior imersão. No caso de visitas a instituições ou sítios históricos, a RA permite ao usuário "sobrepor", em tempo real, o ambiente virtual ao espaço físico onde se encontra, utilizando um dispositivo tecnológico, podendo usar a interface do ambiente real para manusear os objetos reais e virtuais (Silva, 2013). Os benefícios específicos para o patrimônio cultural derivam do gerenciamento de informações ligado à RA, que permite armazenar e administrar grandes quantidades de dados, benéficos para a preservação do patrimônio cultural e o monitoramento sustentável de sua conservação ao longo do seu ciclo de vida. Além disso, estas iniciativas podem promover ontologias de patrimônio cultural com características de RA, permitindo que cidadãos e visitantes acessem prontamente um grande volume de informação que permite o entendimento de seu valor histórico no contexto mais amplo de um conjunto de bens.

A pesquisa ReRealidade foi embasada em revisão bibliográfica sistemática nas principais bases indexadoras sobre a conceituação do uso da RA na arquitetura. Foram testados programas gratuitos (ARCore, ARKit e Vuforia) e elementos digitalizados por fotogrametria. As coordenadas do bem funcionam como marcador (Figura 8).

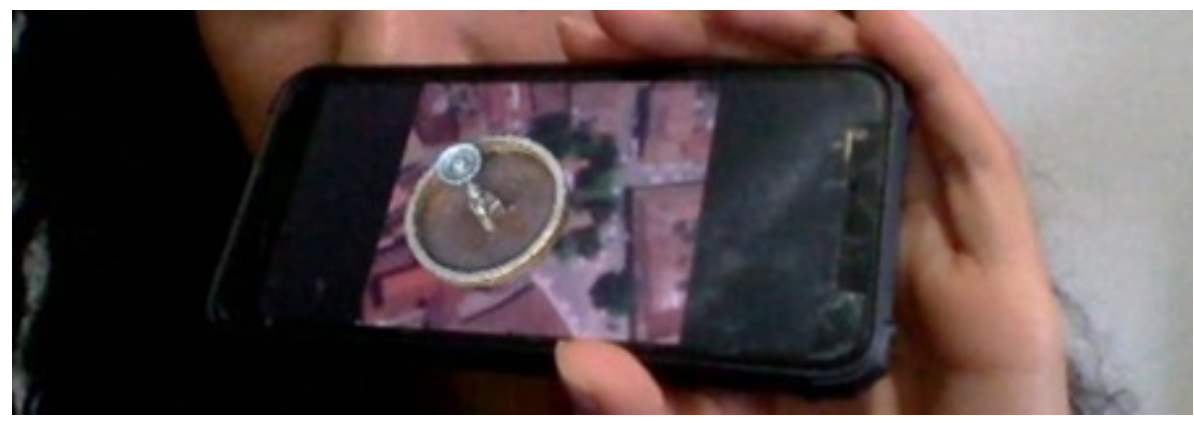

FIGURA 8

Teste do modelo da Fonte da Praça do Coreto em realidade aumentada Fonte: http://labam.dev/Goyaz\%20Digital/ar

A RA permite criar simulações de elementos e detalhes construtivos históricos e de métodos vernaculares de construção; permitindo valorar bens históricos, no sentido de funcionar como fonte de informações sobre eles. Ao final do projeto, foi criado um aplicativo mobile para aumentar o alcance da divulgação dos modelos escaneados (Figura 9). Até o momento, o aplicativo pode ser baixado no GooglePlay por meio da palavra "ReRealidade" e utilizado em celulares Android. 


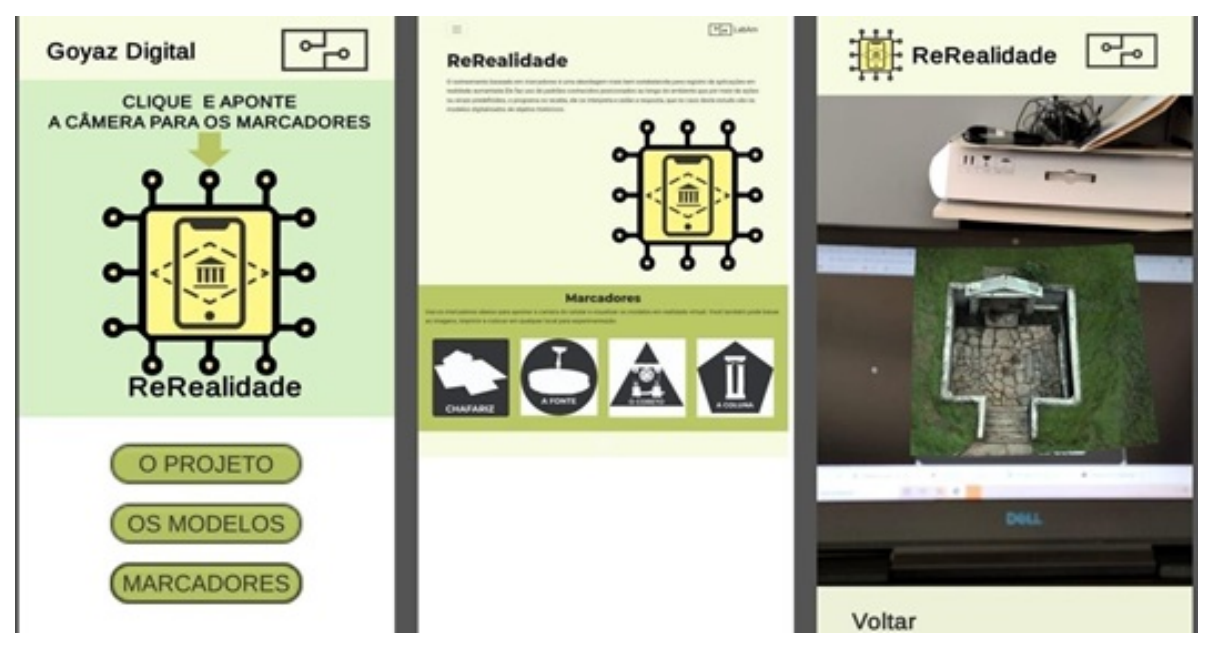

FIGURA 9

Telas do aplicativo ReRealidade

Acervo da pesquisa (2021).

A criação de um aplicativo de RA envolve, em termos gerais, duas tecnologias principais: para a construção da estrutura do aplicativo (como botões, textos, links etc.), foi utilizado o motor de jogos Unity; e para a criação dos experimentos em RA foi utilizado o programa Vuforia. Basicamente, o aplicativo lê um marcador no ambiente físico para acessar conteúdo específico hospedado online (Figura 10). O marcador pode ser uma imagem de qualquer tamanho, criada ou não para tal finalidade, por exemplo, um QR Code, uma logomarca, uma fotografia etc. No caso do projeto ReRealidade, os marcadores são as coordenadas geográficas e o conteúdo acessado são as maquetes virtuais dos elementos urbanos históricos digitalizados durante o projeto ReDigital; de modo que o aplicativo pode ser utilizado de forma remota. No caso do aplicativo Pokémon GO, exemplo mais conhecido do público em geral, o marcador também eram as coordenadas geográficas e o conteúdo acessado eram as animações dos personagens do anime; mas só poderia ser utilizado presencialmente.

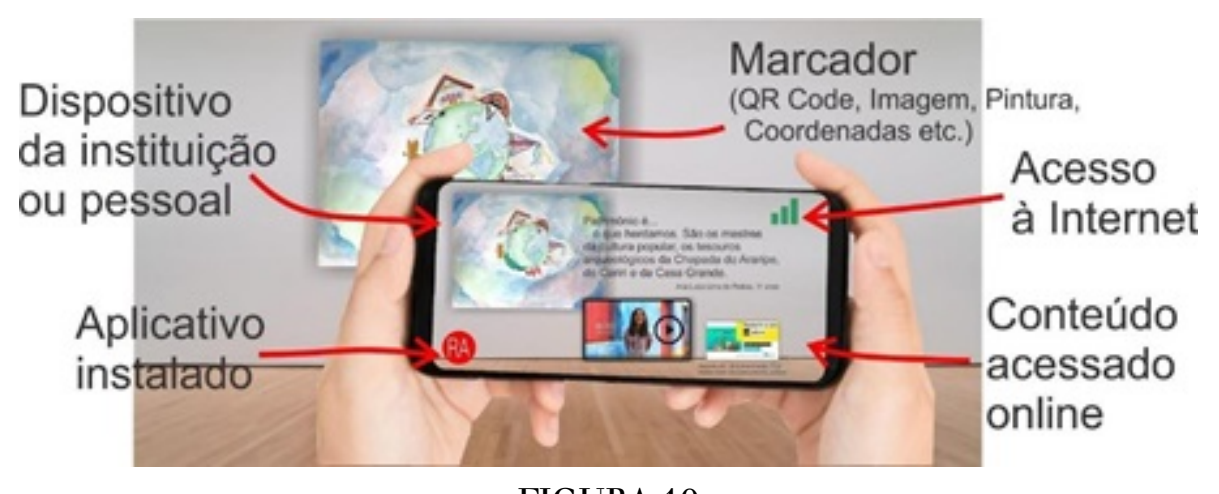

FIGURA 10

Elementos de uma experiência presencial com realidade aumentada Fonte: Acervo da pesquisa (2021).

Essa tecnologia tem muitas utilidades na área do patrimônio cultural. Inclusive, se integrada a outras tecnologias, a Realidade Aumentada pode ser utilizada para reconstruir virtualmente edificações destruídas por intempéries, pelo tempo, por catástrofes naturais ou pela ação humana e para disponibilizar visita virtual ou visita presencial aumentada às mesmas. Dessa forma, a tecnologia auxilia, por exemplo, estudos e visitas que busquem o entendimento do cotidiano da época em que as construções ainda estavam íntegras ou cumpriam suas finalidades originais. 


\section{Gamificação e Serious Games}

A documentação patrimonial por meios digitais não elimina a necessidade dos meios tradicionais, mas contribui significativamente para maior eficiência do processo, seja pela redução dos custos, seja pela maior rapidez de execução. Nesse contexto, a gamificação (inclusão de elementos característicos do universo de jogos nas mais diversas áreas, entre elas a patrimonial e turística) se mostra uma poderosa ferramenta para aumentar o engajamento e a motivação dos visitantes. De modo semelhante, para melhorar a experiência das pessoas em relação ao patrimônio cultural e ao turismo por meio da ludicidade, pode-se contar também com os Serious Games, que, ao contrário da gamificação, possuem uma estrutura própria de jogos, mas priorizam os fins educacionais, e, diferentemente dos jogos comuns, não têm o objetivo primário de entreter. Ou seja, tanto a gamificação quanto os Serious Games fazem a conexão do universo dos jogos com o mundo real; o que muda são os fluxos, que seguem sentidos contrários (Figura 11).

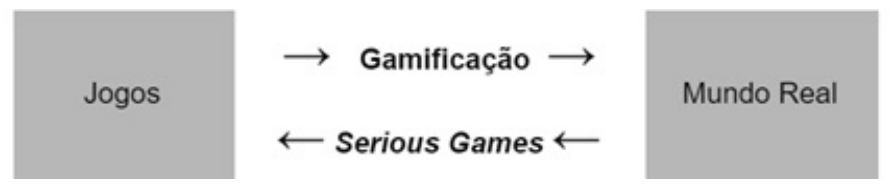

FIGURA 11

Fluxo da conexão do mundo real com o universo dos jogos por meio da gamificação e dos serious games Fonte: Elaborado pelos autores.

Em relação à gamificação como um recurso para o ensino e aprendizagem no campo do patrimônio cultural, um dos exemplos promissores é a plataforma Minecraft, sobretudo sua edição educacional (http:// education.minecraft.net), que tem se destacado como instrumento para a criação de diversas atividades lúdicas relacionadas a bens patrimoniais. Isso é possível porque Minecraft é concebido como um sandbox game, tipo de jogo livre, colaborativo e aberto às proposições de seus usuários.

Um exemplo é a aplicação "No Centro do Património: novos desafios digitais", desenvolvida por Nascimento (2018), que propõe que crianças elaborem um modelo 3D do Mosteiro da Batalha (Porto, Portugal). A intenção da autora é que, após jogarem no mapa Minecraft do Mosteiro da Batalha, as crianças despertem o interesse em visitar presencialmente o monumento com colegas e familiares.

Outra aplicação da plataforma no contexto patrimonial é projeto Create Your Own Museum (http:// education.minecraft.net/OYmxf) que busca aumentar o envolvimento dos alunos com o conteúdo das aulas sobre Martin Luther King Jr., identidade e Direitos Civis. Trata-se de uma atividade com muita liberdade de criação por parte dos alunos, estando condicionada apenas ao grau de profundidade de pesquisa feita por eles.

Aplicado de forma semelhante ao contexto museal, Great Fire 1666 (www.museumoflondon.org.uk/ discover/great-fire-1666) foi encomendado pelo Museu de Londres por ocasião do $350^{\circ}$ aniversário do grande incêndio que afetou a cidade. $\mathrm{O}$ jogo proporciona às pessoas a possibilidade de reviver a história do incêndio, isto é, leva os jogadores a descobrir as causas do terrível evento; ajudar a combater o incêndio e, eventualmente, tentar reconstruir Londres.

E, finalmente, o projeto History Blocks (http://education.minecraft.net/jME69) tem como objetivo orientar professores para que possam conduzir seus alunos na reconstrução virtual de patrimônios da Unesco. As metas de aprendizagem são: (1) conscientização sobre os patrimônios históricos; e (2) compreensão das questões estéticas e culturais e das proporções das edificações. Esse tipo de reconstrução se baseia na observação de fotos antigas de monumentos destruídos (seja por terrorismo, guerras, falta de cuidado ou tragédias naturais). Mesmo não tendo o rigor técnico e científico proposto pela Carta de Sevilha (Carta Patrimonial que trata dos princípios internacionais da arqueologia virtual), os projetos realizados com a edição educacional do Minecraft cumprem seu objetivo de conscientizar e educar a respeito do patrimônio cultural, despertando o interesse e a curiosidade dos educandos. 
Em relação aos Serious Games, Díaz et al. (2014) relatam sobre a elaboração e utilização do jogo sueco de aventura $\mathrm{O}$ Mistério de Elin (Elins Mysterium), por meio de um aplicativo de dispositivos móveis, para a interação com espaços históricos (Figura 12). O aplicativo faz uso de uma plataforma baseada em localização para despertar a fantasia e a curiosidade das crianças sobre o patrimônio cultural. Conforme descrevem, o design de um jogo de mistério funciona como meio para transmitir conteúdo de forma associada à exploração móvel, ao trabalho em equipe e à combinação de mundos virtual e físico. Em Elins Mysterium, os jogadores usam recursos do aplicativo da plataforma e recursos do iPad, como bússola, GPS, reconhecimento de câmera e imagem para resolver quebra-cabeças, procurar símbolos, contar objetos e encontrar edifícios, praças e parques.

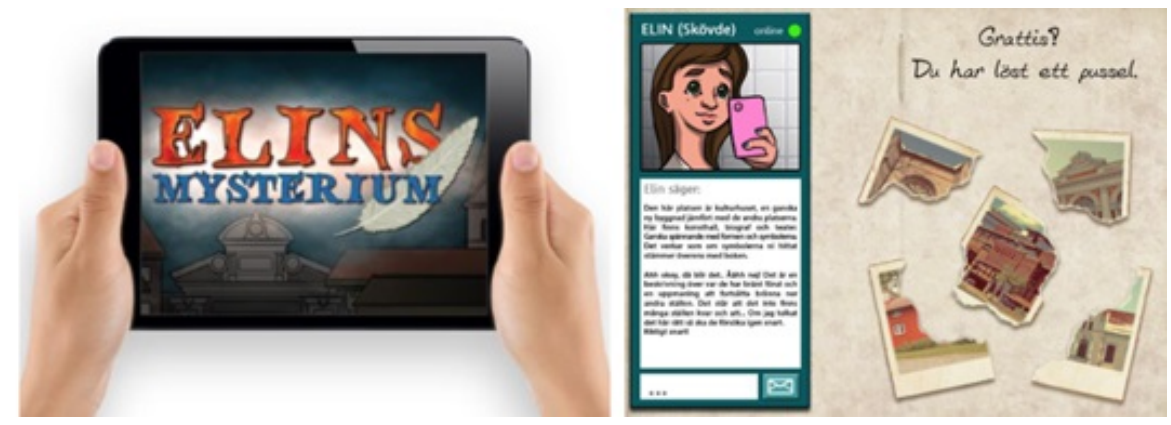

FIGURA 12

Jogo Elins Mysterium - Tela de abertura e Interface do chat Fonte: Díaz et al. (2014).

Quando se trata de gamificação do turismo, Gunnarsson (s.d.) apresenta três maneiras de gamificar um museu ou centro histórico utilizando basicamente papel e caneta, material gráfico fornecido pelo museu, $Q R$ codes, tablets e/ou smartphones:

1. Crianças em idade escolar e famílias em um museu ou centro de arte. Enredo: O local foi roubado na noite anterior e o segurança precisa de ajuda para descobrir o que foi roubado. Ao entrar no museu, o visitante recebe do segurança um bilhete com uma lista de tarefas, com espaços para marcar à medida em que forem sendo finalizadas. $\mathrm{O}$ jogo termina com o cumprimento de todas as tarefas. Recompensas: Um prêmio e uma lembrancinha, retirados na recepção. Tecnologia e materiais: QR Codes impressos e colados em locais estratégicos. Observações: $\mathrm{O}$ aprendizado se dá a partir das pistas espalhadas pelo museu que permitem estudar artefatos para investigar o crime.

2. Crianças em idade escolar em jardins botânicos. Enredo: Estamos em uma pandemia mundial e os jogadores precisam ajudar o cientista a criar uma vacina para salvar a raça humana. $O$ cientista entrega uma lista com os nomes científicos das plantas (em latim) de que precisa para a vacina. O visitante deve identificar onde elas podem ser encontradas nos jardins, anotar o nome popular delas e fazer um esboço de cada espécie para que o cientista tenha certeza de que são as plantas corretas. Dinâmica: A proposta é organizada para ser jogada em grupos que competem entre si, e a equipe vencedora pode ser determinada pela velocidade ou qualidade dos desenhos feitos. Tecnologia e materiais: Embora não seja pensada originalmente para usar tecnologia no processo, a atividade pode ser adaptada e contemplar o uso de smartphones, tablets e QR Codes.

3. Adultos jogando orientação em um museu. Enredo: Os participantes estão presos dentro do museu e a única saída é resolver sete quebra-cabeças conectados a determinados artefatos. A parte divertida do jogo consiste em ser guiado por pistas (frases ou versos enigmáticos) fornecidas por um quebra-cabeça, que indicam o caminho para o próximo artefato com a próxima pista. O jogo termina quando os sete artefatos forem coletados. Recompensa: $\mathrm{O}$ jogador terá descoberto a palavra mágica ou resolvido todos os quebracabeças e deverá mostrar aos funcionários da recepção para receber um selo ou algo que pode entregar no café do museu para uma bebida gratuita, por exemplo. Ou os vencedores têm o nome inscrito na loteria anual do museu, ou recebem um passe de um ano para o museu, ou algum brinde como uma camiseta. Tecnologia e 
materiais: Os sete quebra-cabeças podem ser diferentes e o visitante pode jogar usando papel e caneta ou um smartphone com tecnologia de posicionamento.

Uma Revisão Sistemática da Literatura (RSL) sobre o potencial da gamificação para aumentar a competitividade dos destinos turísticos foi realizada por Souza et al. (2017). Segundo os autores, os primeiros trabalhos sobre gamificação foram publicados em 2011 e tiveram as primeiras abordagens expandidas ao setor do turismo a partir de 2012. Os autores apontam como principais influências positivas da gamificação nos destinos turísticos: (1) Aquisição de competências subjetivas, tais como tomada de decisão, liderança e trabalho em equipe; (2) Aprendizagem via mobile; (3) Promoção do turismo; (4) Descoberta da história, da vida e da identidade locais; (5) Formação e impacto à imagem de destinos/ empresas, formação e difusão de modas e tendências na indústria do turismo; e (6) Experiência de novas atrações e atividades de lazer, vivenciando um destino singular, aumento de visitação, envolvimento dos visitantes e extensão de sua estadia, engajamento e lealdade. Enfim, quando se trata de gamificação as possibilidades são diversas, mas tudo dependerá do conhecimento a respeito das etapas e princípios do design de jogos, do tempo, criatividade e recursos disponíveis.

\section{CONSIDERAÇões FINAIS}

Muitas são as tecnologias com grande potencial junto ao patrimônio cultural. Contudo, sua utilização no Brasil ainda esbarra em dificuldades de implantação e manutenção de ambientes virtuais pelos órgãos governamentais da área. Podemos dizer então que existe um lapso na transferência da tecnologia desenvolvida e testada nas universidades e empresas - para os espaços e instituições de memória. O que inclui questões como o desconhecimento da existência das tecnologias; a falta de profissionais especializados para criação, implementação, alimentação/atualização e manutenção de tais tecnologias; e o pouco financiamento da Cultura em geral. Por isso, é essencial envidar esforços entre instituições de memória e grupos de pesquisa para que se coloque o conhecimento produzido na academia em prática junto à sociedade.

Além disso, como afirma o sociólogo espanhol Manuel Castells (2015a), as gerações mais jovens já pensam de forma digital e são capazes de auto-informar-se, de auto-comunicar-se e de auto-organizar-se por meio da Internet. Sua aprendizagem está dividida entre a escola (que frequentam para obter um diploma) e a Internet, onde se reúnem com grupos informais para aprender (Castells, 2015b). Ocorre um choque entre pensamento e ensino analógico x digital: o método de ensino proveniente da Idade Média não é interativo, entedia os estudantes e 30\% deles abandonam o ensino médio na Europa e nos EUA (Castells, 2015b). A capacidade atual dos estudantes de obter muitas informações simultaneamente reduz a concentração, mas também desenvolve habilidades de recombinação de informações diferentes, base da criatividade que, por sua vez, leva à produção de ideias e conhecimentos novos (Castells, 2015b).

A mesma reflexão é válida para as instituições de memória, por seu caráter de ensino/aprendizagem. De modo que elas precisam atualizar sua metodologia pela incorporação das novas tecnologias a fim de manter o interesse de seus visitantes, principalmente os jovens por seu papel fundamental como futuros guardióes do patrimônio cultural coletivo.

\section{REFERÊNCIAS}

Arruda, A. K. T. (2013). Preservação e gestão do patrimônio construído: a contribuição do Heritage Information System. [Tese de Doutorado, UFBA]. Salvador, BA, Brasil.

Barros, R. (Coord.) (2021). Museus orgânicos. SESC Ceará.

Briggs, A., \& Burke, P. (2004). Uma história social da mídia: de Gutenberg à Internet. Jorge Zahar.

Brito, J.; Coelho, L. (2002) Fotogrametria Digital. Instituto Militar de Engenharia. 
Camargo, A. P. L., \& Santos, I. P. (2005). Bibliotecas virtuais e multimídia. In: Barbosa Filho, A., Castro, C., \& Takashi, T. (Orgs.) (2005). Mídias digitais: convergência tecnológica e inclusão social. (pp. 339-357). Paulinas.

Castells, M. Escola e internet: o mundo da aprendizagem dos jovens. In: Fronteiras do pensamento. [vídeo] 12 de jan. de 2015b. https://youtu.be/J4UUM2E_yFo

Castells, M. O poder da juventude é a autocomunicação. In: Fronteiras do pensamento. [vídeo] 23 de abr. de 2015 a. https://youtu.be/0L9c2h0TTLo

ConservaFAU (s.d.). O levantamento métrico-arquitetônico na conservação do patrimônio. [online] https://conserv afau.wordpress.com/2016/04/15/o-levantamento-metrico-arquitetonico-na-conservacao-do-patrimonio

Díaz, M. G. A., Toftedahl, M., \& Svensson, T. (2014). The Mystery of Elin: incorporating a city cultural program on history and heritage into a pervasive game. [Apresentação de Trabalho]. Interactive Entertainment, Newcastle, Reino Unido.

dos Santos, J. (s.d.). Descrição. https://cultura.sobral.ce.gov.br/projeto/2539/\#/tab=sobre

Gunnarsson, S. B. (s.d.). Gamification and games-based approach to cultural heritage: A practical handbook with guidelines and examples. cinegamification.com

iPatrimônio (s.d.). Goiás - Centro Histórico. www.ipatrimonio.org/Goias-Centro-Historico

Macdonald, L. (Ed.) (2006). Digital heritage: applying digital imaging to cultural heritage. Butterworth-Heinemann.

Mestre Dinha (s.d.). Museus Orgânicos. https://mcmdinha.wixsite.com/museuorganico/museu-organicos

Nascimento, A. S. S. (2018). A Gamificação em Contexto Turístico: O Caso "Dias do Património a Norte". [Dissertação de Mestrado. Faculdade de Letras / Universidade do Porto]. Porto, Portugal. https://repositorioaberto.up.pt/bitstream/10216/117619/2/303285.pdf

Palfrey, J., \& Gasser, U. (2011). Nascidos na era digital: entendendo a primeira geração de nativos digitais. Artmed.

Pratschke, A. (2019). Cultura e mídia digital: do objeto ao sistema. [Apresentação de Powerpoint] IAU-USP.

Quindins, A., \& Sousa, V. P. (2021). Fundação Casagrande: patrimônio e desenvolvimento local. Instituto IEDS. www.youtube.com/watch?v=XUGlEkzd4lM

Silva, A. S. S. D. (2013). Uso de recurso educacional com mídias interativas e integradas on-line em ensino e aprendizagem. [Dissertação de Mestrado Profissional. PPGEC/UNIFEI]. Itajubá, MG, Brasil.

Souza, V. S., Varum, C. M. D. A., \& Eusébio, C. (2017). O Potencial da Gamificação para Aumentar a Competitividade dos Destinos Turísticos: revisão de literatura baseada na Scopus. Revista Turismo em Análise - RTA, 28(1), 91-111. www.revistas.usp.br/rta/article/view/118490/128211

Trivinho, E. (2001). Glocal: para a renovação da crítica da civilização mediática. In: Fragoso, S., \& Fraga Da Silva, D. (Org.) (2001). Comunicação na cibercultura. Unisinos.

Virilio, P. (1993). O espaço crítico.

\section{Notas}

[1] Criação do projeto e manutenção técnica: Caio Cardoso Lucena / Redes sociais e atendimento ao usuário: Cida Barros / Alimentação da plataforma e atendimento ao usuário: Sandra Schmitt Soster. 